Alina Coutinho Rodrigues Feitosa

LUCIANa Nunes SAMPaiO ${ }^{2}$

ana Graciele Lessa Batista ${ }^{3}$

Carla Borges PINHERO ${ }^{3}$

Artigo Original

Keywords

Gestational diabetes/psychology Insulin/administration \& dosage Health education

Fear

Injections, intravenous/psychology

Palavras-chave

Diabetes gestacional/psicologia Insulina/administração \& dosagem

Educação em saúde

Medo

Injeções intravenosas/psicologia

Correspondence

Alina Coutinho Rodrigues Feitosa

Coordenaccão de Ensino e Pesquisa da Maternidade Prof. José Maria de

Magahäes Netto

Rua Marques de Marić, $s / n$ - Pou Miúdo

Zip code: $41500-300$

Salvador (BA), Brazil

Received

07/11/2012

Accepted with modifications

$01 / 21 / 2013$

\section{Frequency of fear of needles and impact of a multidisciplinary educational approach towards pregnant women with diabetes}

\author{
Frequência de medo de agulhas e impacto de uma abordagem \\ educacional multidisciplinar em gestantes com diabetes
}

Abstract

PURPOSE: To evaluate the frequency of fear of needles and the impact of a multidisciplinary educational program in women with pre-gestational and gestational diabetes taking insulin during pregnancy. METHODS: The short Diabetes Fear of Injecting and Self-testing Questionnaire (D-FISQ), composed by two subscales that access fear of self injection (FSI) and fear of self testing (FST), was administered twice during pregnancy to 65 pregnant women with pre-gestational and gestational diabetes: at the first endocrine consult and within the last two weeks of pregnancy or postpartum. An organized multidisciplinary program provided diabetes education during pregnancy. Statistical analysis was carried out by Wilcoxon and McNemar tests and Spearman correlation. A p<0.05 was considered to be significant. RESULTS: Data from the short D-FISQ questionnaire shows that $43.1 \%$ of pregnant women were afraid of needles in the first evaluation. There was a significant reduction in scores for FSI and FST subscales between the first and second assessments (first FSI 38.5\% compared with second 12.7\%, $\mathrm{p}=0.001$; first FST 27.7\% compared with second FST $14.3 \%, p=0.0121$. CONCLUSIONS: The fear of needles is common in pregnant women on insulin therapy and an organized multidisciplinary educational diabetes program applied during pregnancy reduces scores of such fear.

\section{Resumo}

OBJETIVO: Avaliar a frequência do medo de agulhas e o impacto de um programa educacional multidisciplinar em mulheres com diabetes pré-gestacional e gestacional em uso de insulinas durante a gravidez. MÉTODOS: $\bigcirc$ questionário Diabetes Fear of Injecting and Self-testing Questionnaire (D-FISQ) resumido, composto por duas subescalas que acessam o medo de injeções (FSI) e o medo da automonitoração (FST), foi administrado duas vezes durante a gestação de 65 mulheres com diabetes pré-gestacional e gestacional: na primeira consulta endocrinológica e dentro das últimas duas semanas de gestação ou pós-parto. Durante a gravidez, as gestantes foram submetidas a um programa multidisciplinar sistematizado para prover educação em diabetes. A análise estatística foi realizada por meio dos testes de Wilcoxon e McNemar e a correlação de Spearman. Valor $\mathrm{p}<0,05$ foi considerado como significativo. RESULTADOS: A aplicação do questionário D-FISQ resumido indicou que 43,1\% das gestantes apresentavam medo de agulhas na primeira avaliação. Houve significativa redução nos escores das subescalas FSI e FST entre a primeira e segunda avaliação (primeiro FSI 38,5\% comparado com o segundo 12,7\%, p=0,001; primeiro FST 27,7\% comparado com segundo FST 14,3\%, p=0,012). CONCLUSÃO: $\bigcirc$ medo de agulhas é frequente em gestantes em uso de terapia com insulina, e um organizado programa multidisciplinar educacional em diabetes aplicado durante a gestação reduz os escores do medo.
Study carried out at department of Obstetrics and Gynecology, Maternidade de Referência Professor José Maria de Magallhães Netto and Departament of Internal Medicine, Hospital Santa Izabel - Salvador (BA), Brazil.

'Ambulatory of Endocrinopathies in the Departament of Obstetrics, Maternidade de Referência Professor José Maria de Magalhães Netto Salvador (BA), Brazil.

2Obstetrics and Gynecology, Maternidade de Referência Professor José Maria de Magalhães Netto - Salvador (BA), Brazil. ${ }^{3}$ Ambulatory of Endocrinopathies in Pregnancy, Maternidade de Referência Professor José Maria de Magalhães Netto - Salvador (BA), Brazil. Conflict of interest: none 


\section{Introduction}

Although insulin treatment is the mainstay of diabetes management in type 1 and type 2 diabetes with secondary pancreatic insufficiency or uncontrolled glycemia, poor adherence to insulin injections occurs due to factors such as fear of insulin or fear of needles ${ }^{1}$. Patient barriers to accept insulin initiation/treatment also include fear of hypoglycemia, weight gain and reluctance to adapt the inflexible timing of scheduled insulin doses ${ }^{2}$. Patients often consider insulin as the last treatment option, as a form of punishment or failure of self control $^{3}$, but fear of needles and its association with pain remains as one of the most important factors. This fear has a negative impact on the treatment of patients with diabetes ${ }^{1}$.

In women with pre-gestational diabetes (PGD) and gestational diabetes (GD), insulin therapy is the treatment of choice for blood glucose control and prevention of poor fetal outcomes ${ }^{4-8}$. Insulin therapy is essential for pregnant women who have been on insulin prior to pregnancy, and is the next step to achieve glycemic control in women with gestational diabetes and type 2 diabetes who did not obtain optimal glycemic control after one or two weeks of healthy lifestyle changes 9 . Even when oral hypoglycemic agents are used as an alternative therapy for glycemic control in women with gestational diabetes, supplemental insulin is required to achieve target levels of glucose in 20.9-46.3\% of those using metformin ${ }^{10,11}$ and $4 \%$ of those on glyburide ${ }^{12}$.

Extreme fear of self-injecting insulin (injection phobia) is likely to compromise glycemic control as well as to cause psychological distress ${ }^{1,13}$. Likewise, fear of self monitoring of blood glucose (SMBG) or finger prick can be a source of distress and may seriously stop self-management. Evidence suggests that fear of blood and injury is associated with less frequent self-testing ${ }^{8,14}$ and poor glycemic control ${ }^{14}$. In pregnancy, when glycemic control must be more strict ${ }^{9}$, intensive basal-bolus insulin regimen with at least three daily injections of insulin and frequent self-monitoring (three to eight times a day) are, in general, the methods used to achieve optimal blood glucose levels? ${ }^{9}$. The fear of needles can hamper the intensive insulin therapy and affect adherence and glycemic control of women with PGD diabetes, and especially those with GD.

The Diabetes Fear of Injecting and Self testing Questionnaire (D-FISQ) has been validated in children and adults with diabetes ${ }^{15,16}$. The D-FISQ is a 30 -item self-report questionnaire consisting of two subscales that measure fear of self-injecting insulin (FSI) and fear of self-testing (FST), the latter measuring fear of blood glucose testing ${ }^{13}$. The short version of the D-FISQ has been proved useful for research with insulin-treated diabetes patients ${ }^{17}$.
For pregnant women who started on insulin therapy in the antenatal care, learning and acquiring skills as to insulin injections and self-monitoring should be fast because strict control must be achieved in the shortest time possible. These characteristics increase difficulties and certainly worsen adherence. Our objectives were to evaluate the frequency of fear of needles among diabetic pregnant women population and the influence of the type of diabetes in pregnancy (gestational or pre-gestational) and the fear of needles in order to determine the impact of an educational diabetes program during pregnancy as to such fear.

\section{Methods}

The present report is a prospective cohort of pregnant women aged $18-45$ years with both pre-gestational (PGD) and gestational diabetes (GD). They were eligible to participate if they were on insulin by injection and if they had antenatal and endocrine appointments in the institution. Potential subjects were approached by study personnel in regularly scheduled clinic visits, and consent was obtained. A total of 65 patients with diabetes mellitus volunteered to participate and 63 completed follow-up. Gestational diabetes mellitus was defined according to theAmerican Diabetes Association criteria by 2-h 75-g OGTT as at least two values higher than a fasting glucose of $95 \mathrm{mg}$ per deciliter (5.3 $\mathrm{mmol}$ per liter), a 1 -h glucose of $180 \mathrm{mg}$ per deciliter (10 mmol per liter), or a 2-h glucose of $155 \mathrm{mg}$ per deciliter $(8.6 \mathrm{mmol} \text { per liter })^{18}$.

This study was carried out at Maternidade Professor José Maria de Magalhães Netto, a tertiary referral public academic institution. This maternity is a reference for high risk pregnancy in the state of Bahia and the patients were recruited from the Ambulatory of Endocrinopathies in Pregnancy, a multidisciplinary outpatient clinic of the maternity. All health care professionals of the multidisciplinary team have access to the ambulatory medical record. The study was approved by the institutional review board.

\section{Participants and procedures}

Insulin therapy was only continued if previously used by women with both gestational and pre-existing diabetes, and was started among those who had not achieved glycemic control after one to two weeks of lifestyle changes. The goals of the treatment were the achievement of a fasting blood glucose concentration of 63 to $90 \mathrm{mg}$ per deciliter (mmol per liter), preprandial blood glucose concentration of 65 to $99 \mathrm{mg}$ per deciliter (mmol per liter) and a 2-hour postprandial blood glucose concentration of less than $126 \mathrm{mg}$ per deciliter. Insulin regimens were based on predicted total daily insulin requirements according to current weight and stage of pregnancy. We 
used human NPH and regular insulin as a basal-bolus scheme given in two to four injections a day. Basal insulin $(\mathrm{NPH})$ was given 30 minutes before breakfast, lunch and at bedtime, and was adjusted by 2 to $10 \mathrm{U}$ at a time to achieve, respectively, pre-lunch, pre-dinner and fasting capillary blood glucose target. Pre-meal regular insulin was given in a fixed dose, mixed with NPH in the same syringe, 30 minutes before the meal, and was adjusted by 2 to $10 \mathrm{U}$ at a time to achieve postprandial blood glucose target. Insulin doses were adjusted weekly or biweekly by an endocrinologist. Insulin was injected in the arms, legs, buttocks and abdomen, when comfortable. All patients were counseled to rotate the placement of insulin injections and to do intensive self monitoring of capillary blood glucose with at least three finger pricks per day.

\section{Multidisciplinary educational approach}

Antenatal care was provided by a multidisciplinary team composed by endocrinologists, obstetricians, nurse educators, dietitians and social workers. Endocrine and nurse consultation took place every two weeks, and appointments with dietitians and obstetrician happened every month. At the first endocrine consultation, the endocrinologist provided 20 to 30 minutes of individualized counseling using principles of adult education. Patients were taught about the importance of glycemic control during pregnancy, the impact of hyperglycemia in the fetus and mother and how to control hyperglycemia using insulin, dietary plan and healthy life style.

Explanations about blood glucose targets and ideal weight gain during pregnancy were given for each patient. We calculated the basal-bolus insulin scheme using pre-pregnant body weight and advised patients to do self-monitoring of blood glucose levels three times a day, during suggesting symptoms of hypoglycemia, and eight times a day (including bed time and at $3 \mathrm{am}$ ) once a week. Patients should record capillary blood glucose measures in a standardized diary. Patients were instructed to recognize symptoms of hypoglycemia and were trained to promptly respond to early autonomic or neuroglycopenic symptoms. Educational printed material about healthy food choices, artificial sweeteners, insulin use and hypoglycemia was provided to each pregnant woman. They were instructed to carry a diabetes orientation card and $15 \mathrm{~g}$ of oral glucose in order to recover from a hypoglycemia episode.

In subsequent visits, endocrinologists asked about insulin use, place of insulin injections, SMBG, symptoms or signs of hypoglycemia and adherence to dietary recommendations. We checked the acquired skills in adapting the timing and content of meals to fixed doses of insulin. Patients were questioned about ideal glycemic targets and weight gain and their results were compared with ideal blood glucose levels and weight gain. Each patient had to circle registered capillary blood glucose out of the target and they were taught to identify the reasons for it and how to provide corrections in a problem-solving manner. When a hypoglycemic episode occurred, the patient was led to identify the reason(s) that best explained it in order to prevent a new episode.

In the first nutritional consultation, a registered dietitian (RD) evaluate the caloric intake based on a 24-hour food recall, gave individualized dietary advice and a written dietary plan with meals. The written dietary plan consisted of three main meals and two or three snacks per day. The RD considered pre-pregnancy body weight and weight gain during the current pregnancy to elaborate a dietary plan. Subsequent monthly visits until delivery reviewed adherence to written dietary plan, food preparation, food choices and monitor weight gain.

In the first nurse consultation, a registered nurse (RN) gave advice about the importance of strict glycemic control and risk of hypoglycemia in pregnant women with diabetes. Patients were instructed and trained on how to do SMBG and insulin injections. They were also instructed on how to record capillary blood glucose measurements in a standardized diary. In subsequent biweekly visits, the RN reviewed the SMBG diary and the acquired skills, asked about doubts and cleared missing or misunderstood information. The patient were guided as to signs and symptoms of hypoglycemia, risk factors and the need to carry the diabetes orientation card and absorbable carbohydrates at all times. They were instructed to share advice on hypoglycemia with family members for prompt treatment of severe hypoglycemic episodes. All acquired knowledge was reinforced every visit.

\section{Data collection procedure and measures}

The short version of the D-FISQ questionnaire was administered to each subject by a trained interviewer. The short D-FISQ is a 15 -item self-report questionnaire consisting of two subscales that measure fear of self-injecting (6-item subscale) and fear of self-testing (9-item subscale), the latter measuring fear of blood glucose testing ${ }^{13,17}$. The items were scored on a 4-point Likert scale, ranging from zero (almost never) to three (almost always). The short D-FISQ was administered to each pregnant woman as follows: for women with pregestational diabetes already on insulin, it was applied in the first endocrine appointment. For women with GD and PGD who started on insulin therapy during pregnancy, the questionnaire was administered two weeks after the onset of insulin therapy.

A total score was obtained for each questionnaire by summing the item scores. A score $\geq 6$ was considered positive for fear of needle, as it has previously shown to be 
consistent with needle fear in an adult population ${ }^{15}$. These questionnaires were administered for 65 pregnant women.

Additionally, investigators reapplied the questionnaire for each subject in the final pregnancy period (in the last two weeks) or in the early postpartum period (the first two weeks).

\section{Data analyses}

Statistical analyses were performed using SPSS 13.0 for Windows. Values are expressed as mean \pm standard deviation for normally distributed data or as median and interquartile range for skewed data. Spearman correlation coefficients were calculated to determine associations between different variables. The Wilcoxon test was used to compare paired continuous variables (FSI and FST in the first and second assessments) and the McNemar test served to compare paired dichotomous variables (FSI or FST $\geq 6$ in the first and second assessments). Differences were considered significant when $\mathrm{p}<0.05$.

\section{Results}

A total of 65 pregnant women were included. The median and interquartile range age of the subjects was 33 (interquartil interval: $27.5-37.5$ years). Forty patients (61.5\%) had diabetes prior to pregnancy: 9 had type 1 and 31 had type 2 diabetes. Gestational age at the first administration of the questionnaire was $26.9 \pm 7.6$ weeks gestation. Sixty three patients completed follow-up. The median follow-up period was $9.7 \pm 6.9$ weeks gestation, and the administration of the questionnaire for the second time was in median $36.7 \pm 2.0$ weeks gestation. In four

Table 1. Subscale scores of fear of self-Injection and fear of self-testing compatible with fear of needles (score $\geq 6$ )

\begin{tabular}{lccccccccc}
\hline & \multicolumn{3}{c}{ First assessment $(\mathrm{n}=65)$} & \multicolumn{3}{c}{ Second assessment $(\mathrm{n}=63)$} \\
\cline { 2 - 10 } & \multicolumn{3}{c}{ FSI } & \multicolumn{2}{c}{ FST } & \multicolumn{3}{c}{ FSI } & \multicolumn{3}{c}{ FST } \\
\cline { 2 - 9 } & $\mathrm{n}$ & $\%$ & $\mathrm{n}$ & $\%$ & $\mathrm{n}$ & $\%$ & $\mathrm{n}$ & $\%$ \\
\hline Total & 25 & 38.5 & 18 & 27.7 & $8^{\star}$ & 12.7 & $9 \dagger$ & 14.3 \\
PGD $(\mathrm{n}=40)$ & 16 & 40.0 & 13 & 32.5 & 6 & 15.4 & 6 & 15.4 \\
GD $(\mathrm{n}=25)$ & 7 & 28.0 & 7 & 28.0 & 2 & 8.3 & 3 & 12.5 \\
\hline
\end{tabular}

PGD: pre-gestational diabetes mellitus; GD: gestational diabetes mellitus; FSI: fear of self-injection; FST: fear of self-testing: McNemar test: ${ }^{*} \mathrm{p}=0.001$ for differences between first and second FSI assessment; ${ }^{\dagger} p=0.012$ for differences between first and second FST assessment. patients, the questionnaire was applied at postpartum. The participation rate was $>95 \%$ of those who agreed to participate.

The short D-FISQ indicated that $43.1 \%$ of pregnant women had significant FSI or FST in the first evaluation ( $\geq 6$ points). The comparison between frequency of fear of needles in PGD and GD did not reveal differences. There was a significant reduction in FSI and FST scores between the first and second assessments. Comparison of FSI and FST subscale scores are shown in Table 1. No fear at all on both subscales was present in $18.5 \%$ $(12 / 65)$ in the first assessment, and in $42.9 \%(27 / 63)$ in the second assessment.

Descriptive statistics and distributions of the scores are demonstrated in Table 2. There was no correlation between FSI and FST scores with doses of insulin and maternal age (data not shown).

\section{Discussion}

Injection phobia is a severe and limiting fear of needles classified as an anxiety disorder in the Diagnostic and Statistical Manual of Mental Disorders IV (DSM-IV-TR). The estimated prevalence of blood and injection phobia in pregnancy is $7.2 \%{ }^{19}$, and women with this anxiety disorder present increased risk for adverse obstetric outcomes, premature delivery and higher neonatal morbidity ${ }^{20}$. Fear is a different emotion, not as severe as phobia, but it may hamper therapy in patients that are on insulin therapy. Fear of needles during pregnancy is a relatively unexplored subject in literature and, to our knowledge, this is the first study that assesses fear of needles among women with diabetes during pregnancy. Considering that the maintenance of a tight control of blood glucose during pregnancy is essential to reduce complications of diabetes in the offspring, the detection of pregnant women who are afraid of injections is extremelly important.

The fear of needles is often neglected ${ }^{21}$, but this study has shown that the short D-FISQ can help identify pregnant women with diabetes who may have FSI with or without FST by means of a rapid and practical tool, which can be part of a prenatal appointment. The frequency of such fear in this study was higher

Table 2. Fear of self-injection and fear of self-testing scores in first and second assessments

\begin{tabular}{|c|c|c|c|c|c|c|c|c|c|c|c|c|}
\hline & \multicolumn{6}{|c|}{ First assessment $(n=65)$} & \multicolumn{6}{|c|}{ Second assessment $(n=63)$} \\
\hline & \multicolumn{2}{|c|}{ FSI } & \multicolumn{2}{|r|}{ FST } & \multicolumn{2}{|c|}{ Total score } & \multicolumn{2}{|c|}{ FSI } & \multicolumn{2}{|c|}{ FST } & \multicolumn{2}{|c|}{ Total score } \\
\hline & Mean $\pm S D$ & Median (IQ) & Mean \pm SD & Median (IQ) & Mean $\pm S D$ & Median (IQ) & Mean $\pm S D$ & Median (IQ) & Mean \pm SD & Median (IQ) & Mean \pm SD & Median (IQ) \\
\hline Total & $5.2 \pm 6.1^{\star}$ & $3.0(0-8.5)$ & $5.3 \pm 7.5 \dagger$ & $0(0-8.5)$ & $10.5 \pm 12.3 \neq$ & $5.0(1.0-18.0)$ & $2.2 \pm 4.3^{\star}$ & $0(0-3.0)$ & $2.5 \pm 5.0^{\dagger}$ & $0(0-2.0)$ & $4.8 \pm 8.8^{\ddagger}$ & $1(0-5.0)$ \\
\hline PGD & $5.9 \pm 6.4^{\star}$ & $3.5(0-9.0)$ & $5.9 \pm 8.2 \dagger$ & $2.0(2.0-10.7)$ & $11.8 \pm 12.7 \neq$ & $6.5(2.0-20.5)$ & $2.6 \pm 4.9^{\star}$ & $0(0-4.0)$ & $2.5 \pm 4.8^{\dagger}$ & $0(0-2.0)$ & $5.1 \pm 9.4^{\ddagger}$ & $1(0-5.0)$ \\
\hline GD & $4.2 \pm 5.6^{\star}$ & $2.0(0-6.0)$ & $4.3 \pm 6.4 \dagger$ & $1.0(0-5.5)$ & $8.5 \pm 11.4 \neq$ & $4.0(0.5-12.5)$ & $1.7 \pm 3.2^{\star}$ & $0(0-2.0)$ & $2.7 \pm 5.3^{\dagger}$ & $0.5(0-2.0)$ & $4.3 \pm 8.0^{\ddagger}$ & $1(0-5.0)$ \\
\hline
\end{tabular}

PGD: pre-gestational diabetes mellitus; GD: gestational diabetes mellitus; FSI: fear of self-injection; FST: fear of self-testing; $1 Q$ : interquartil interval; SD: standard deviation; Wilcoxon test: ${ }^{*} p<0.001$ for differences between first and second FSI assessment; ${ }^{\dagger} p<0.001$ for differences between first and second FST assessment; ${ }^{\ddagger} p<0.001$ for differences between total scores in first and second assessments. 
$(43.1 \%)$ than among adults ${ }^{15}$. This finding may reveal a specific characteristic of the analyzed sample or represent the fear of needles and superimposed fear of effects of diabetes during pregnancy. We expected that the PGD patients had were less afraid of needles than those with GD, because of the previous experience with the disease and the treatment. The similar frequency may have been caused by the limited sample size to demonstrate differences, but the results that we found demonstrate the need to investigate fear in both groups with similar motivation. The initiation of insulin therapy during pregnancy and the optimization of treatment in previous users of insulin aim to lead to a rapid glycemic control. However, the need for fast control and maintenance of strict goals ${ }^{9}$ require complex insulin regimen, which probably hamper the treatment. Multiple daily doses, high doses, and rapid dose adjustments make adherence to insulin therapy difficult and increase the risk of hypoglycemia. These factors require more injections and finger pricks per day, and can justify the development or intensification of fear of needles in both PGD and GD patients.

The reapplication of the questionnaire after the multidisciplinary approach revealed a significant reduction in scores concerning fear of needles. This finding suggests that an organized education program helps reduce fears, and probably improves adherence to therapy, and also strict blood glycemic control. Some might say that the reduction in scores concerning the fear of needles could be a result of simply getting used to self-injecting rather than the education program itself, but it does not explain the reductions in scores of pregnant women with PGD, already accustomed to the self-injection.

There are some limitations to our study. We did not assess the impact of the educational program on glycemic control or on weight at birth. Fear of injection is associated with poor glycemic control, clinical complications, poor general well-being and health status in non-pregnant patients with diabetes ${ }^{1}$. Therefore, we hypothesized that the same association could be present in both PGD and GD patients. Larger population samples would probably be needed to assess whether or not there are differences.

We conclude that the identification of pregnant women who are afraid of injections through the short D-FISQ questionnaire is practical and can be incorporated into the antenatal care of women with diabetes. The application of a multidisciplinary educational program can reduce the scores of fear of injections. We recommend systematic evaluation concerning the fear of needles in pregnant women with diabetes and insulin therapy use to identify those with high scores, thus giving space to the establishment of special attention that promotes significant improvement as to fear.

\section{Acknowledgments}

To Gilson Feitosa, professor of the Bahiana Medical School and Public Health, for the consultation on this project, and the collaborators of the maternity hospital.

\section{References}

1. Fu AZ, Qiu Y, Radican L. Impact of fear of insulin or fear of injection on treatment outcomes of patients with diabetes. Curr Med Res Opin. 2009;25(6): 1413-20.

2. Ross SA, Tildesley HD, Ashkenas J. Barriers to effective insulin treatment: the persistence of poor glycemic control in type 2 diabetes. Curr Med Res Opin. 2011 ;27(Suppl 3):13-20.

3. Tan AM, Muthusamy L, Ng CC, Phoon KY, Ow JH, Tan NC. Initiation of insulin for type 2 diabetes mellitus patients: what are the issues? A qualitative study. Singapore Med J. 2011 ; 52(11):801-9.

4. Negrato CA, Mattar R, Gomes MB. Adverse pregnancy outcomes in women with diabetes. Diabetol Metab Syndr. 2012;4(1):41.

5. Crowther CA, Hiller JE, Moss JR, McPhee AJ, Jeffries WS, Robinson JS, et al. Effect of treatment of gestational diabetes mellitus on pregnancy outcomes. N Engl J Med. 2005;352(24):2477-86.

6. Landon MB, Spong $C Y$, Thom E, Carpenter MW, Ramin SM, Casey $B$, et al. A multicenter, randomized trial of treatment for mild gestational diabetes. N Engl J Med. 2009;361 (14):1339-48.

7. Wyatt JW, Frias JL, Hoyme HE, Jovanovic L, Kaaja R, Brown F, et al. Congenital anomaly rate in offspring of mothers with diabetes treated with insulin lispro during pregnancy. Diabet Med. $2005 ; 22(6): 803-7$.

8. International Association of Diabetes and Pregnancy Study Groups Consensus Panel, Metzger BE, Gabbe SG, Persson B, Buchanan TA, Catalano PA, et al. International association of diabetes and pregnancy study groups recommendations on the diagnosis and classification of hyperglycemia in pregnancy. Diabetes Care. 2010;33(3):676-82.

9. Hone J, Jovanovic L. Approach to the patient with diabetes during pregnancy. J Clin Endocrinol Metab. 2010;95(8):3578-85.

10. Tertti K, Ekblad U, Koskinen P, Vahlberg T, Rönnemaa T. Metformin vs. insulin in gestational diabetes. A randomized study characterizing metformin patients needing additional insulin. Diabetes Obes Metab. 2013;15(3):246-51.

11. Rowan JA, Hague WM, Gao W, Battin MR, Moore MP, MiG Trial Investigators. Metformin versus insulin for the treatment of gestational diabetes. N Engl J Med. 2008;358(19):2003-15.

12. Langer $O$, Conway DL, Berkus MD, Xenakis EM, Gonzales $O$. A comparison of glyburide and insulin in women with gestational diabetes mellitus. N Engl J Med. 2000;343(16):1134-8. 
13. Mollema ED, Snoek FJ, Pouwer F, Heine RJ, van der Ploeg HM. Diabetes Fear of Injecting and Self-Testing Questionnaire: a psychometric evaluation. Diabetes Care. 2000;23(6):765-9.

14. Berlin I, Bisserbe JC, Eiber R, Balssa N, Sachon C, Bosquet F, et al. Phobic symptoms, particularly the fear of blood and injury, are associated with poor glycemic control in type I diabetic adults. Diabetes Care. 1997;20(2):176-8.

15. Mollema ED, Snoek FJ, Adèr HJ, Heine RJ, van der Ploeg HM. Insulin-treated diabetes patients with fear of self-injecting or fear of self-testing: psychological comorbidity and general well-being. J Psychosom Res. 2001;51(5):665-72.

16. Simmons JH, McFann KK, Brown AC, Rewers A, Follansbee D, Temple-Trujillo RE, et al. Reliability of the Diabetes Fear of Injecting and Self-Testing Questionnaire in pediatric patients with type 1 diabetes. Diabetes Care. 2007;30(4):987-8.
17. Goudswaard AN, Stolk RP, Zuithoff P, de Valk HW, Rutten GE. Starting insulin in type 2 diabetes: continue oral hypoglycemic agents? A randomized trial in primary care. J Fam Pract. 2004;53(5):393-9.

18. American Diabetes Association. Diagnosis and classification of diabetes mellitus. Diabetes Care. 2009;32(Suppl 1):S62-7.

19. Lilliecreutz C, Sydsiö G, Josefsson A. Obstetric and perinatal outcomes among women with blood-and injection phobia during pregnancy. J Affect Disord. 2011;129(1-3):289-95.

20. McAllister N, Elshtewi M, Badr L, Russell IF, Lindow SW. Pregnancy outcomes in women with severe needle phobia. Eur J Obstet Gynecol Reprod Biol. 2012;162(2): 149-52.

21. Hamilton JG. Needle phobia: a neglected diagnosis. J Fam Pract. 1995;41(2): 169-75. 